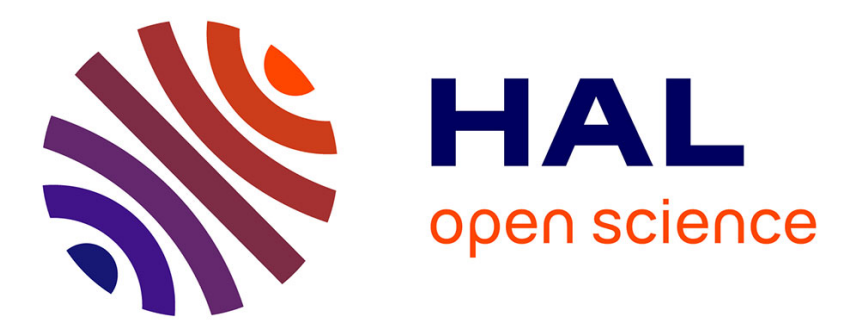

\title{
Condensation of Pure and Mixture of Hydrocarbons in a Compact Heat Exchanger: Experiments and Modelling
}

Bernard Thonon, André Bontemps

\section{To cite this version:}

Bernard Thonon, André Bontemps. Condensation of Pure and Mixture of Hydrocarbons in a Compact Heat Exchanger: Experiments and Modelling. Heat Transfer Engineering, 2002, 23 (6), pp.3-17. 10.1080/01457630290098718 . hal-00184122

\section{HAL Id: hal-00184122 \\ https://hal.science/hal-00184122}

Submitted on 6 Feb 2020

HAL is a multi-disciplinary open access archive for the deposit and dissemination of scientific research documents, whether they are published or not. The documents may come from teaching and research institutions in France or abroad, or from public or private research centers.
L'archive ouverte pluridisciplinaire HAL, est destinée au dépôt et à la diffusion de documents scientifiques de niveau recherche, publiés ou non, émanant des établissements d'enseignement et de recherche français ou étrangers, des laboratoires publics ou privés. 


\title{
Condensation of Pure and Mixture of Hydrocarbons in a Compact Heat Exchanger: Experiments and Modelling
}

\section{B. THONON}

CEA-Grenoble, GRETh, Grenoble, France

\author{
A. BONTEMPS \\ Université Joseph Fourier Grenoble, LEGI-GRETh, Grenoble, France
}

This article presents a study on heat transfer in condensation of pure and mixtures of hydrocarbons in a compact welded plate heat exchanger. Three pure fluids (pentane, butane, and propane) and two mixtures (butane + propane) have been used. The operating pressure ranges from 1.5 to 18 bar. For pure fluids, two heat transfer mechanisms have been identified. For low Reynolds numbers, the condensation occurs almost filmwise and the heat transfer coefficient decreases with increasing Reynolds number. For higher values of the Reynolds number, the heat transfer coefficient increases gently. The transition between the two regimes is between $R e=100$ and 1,000 and depends on the operating conditions. For mixtures, the behavior is different. For low Reynolds numbers, mass transfer affects heat transfer and reduces the heat transfer coefficient by a factor of up to 4. Correlations for filmwise and in-tube condensation do not predict the results accurately, and a specific correlation is proposed for pure fluid condensation. For mixtures, the condensation curve method does not allow mass transfer effects to be taken into account, and more work is required to establish an accurate predictive model.

Condensation occurs in many industrial processes, but rarely with pure fluids. The fluids encountered are mixtures and often noncondensable gases are present, and this makes the condensation process very complex.

This project, JOE3-CT97-0062, has been partially supported by the EC, within the frame of the Non-nuclear Energy Programme. The authors gratefully acknowledge Alfa-Laval Vicarb for supporting this study and coordinating the European project.

Address correspondenc e to Dr. B. Thonon, CEA-Grenoble, GRETh, 17 rue des martyrs, 38054 Grenoble, France. E-mail: thonon@ cea.fr
In the case of mixtures or in the presence of a noncondensable gas, the vapor condensing must diffuse through the gas to the interface. This requires a partial pressure gradient toward the interface.

The partial pressure of the vapor falls from a constant value at a rather large distance from the interface to a lower value at the interface. Correspondingly, the accompanying saturation temperature also falls toward the interface. Therefore, during condensation the condensing vapor arrives by diffusion at the condensate surface, and it is the thermal resistance in the vapor that limits 
the process. Hence, in order to improve the heat transfer, one must reduce the thermal resistance on the vapor side.

Several factors can enhance the condensation process by reducing the vapor-side resistance. During condensation of mixtures or of vapors that contain noncondens ables, the heat transfer on the vapor side can be improved by raising the vapor velocity. It has been shown that the heat transfer coefficient can be improved by approximately $30 \%$ by increasing the vapor velocity. The use of finely undulated surface can also achieve significant augmentations in heat transfer during condensation. It has been shown that corrugation can promote turbulent equilibrium between the phases and thus contribute to the increase in heat transfer.

Compact heat exchangers are characterized by small hydraulic diameters (1-10 mm), and there is no reliable design method to estimate heat transfer coefficients during condensation in such small passages. In the open literature, condensation of mixtures and of vapor in the presence of noncondensable s has been studied, but essentially for conventional geometries (plain tubes), and only a few results have been published with fluids representative of actual process conditions (hydrocarbons).

\section{HEAT TRANSFER IN CONDENSATION}

\section{Gravity-Controlled Regime}

For the gravity-controlle d regime, the Nusselt theory for a plain wall allows the local heat transfer coefficient to be calculated. The average heat transfer coefficient is given by [1]

$\alpha_{\mathrm{Nu}}=$ Co $1.47 \operatorname{Re}_{L}^{-1 / 3}$ where Co is a physical property number:

Co $=\lambda_{L}\left[\frac{\mu_{L}^{2}}{\rho_{L}\left(\rho_{L}-\rho_{G}\right) g}\right]^{-1 / 3}$

The film Reynolds number is calculated by

$\operatorname{Re}_{L}=\frac{4 \dot{m}_{L} D_{h}}{\mu_{L} P}$

where $P$ denotes the wetted perimeter (for flat channels twice the plate width).

The Nusselt theory is valid only if the liquid film is smooth, but for film Reynolds numbers over 30, waves appear at the interface and increase the heat transfer coefficient. Kutatelatze has proposed a modified Nusselt correlation. The average heat transfer coefficient is given by [1]

$\alpha_{\mathrm{Ku}}=\operatorname{Co} \frac{\operatorname{Re}_{L}}{1.08 \operatorname{Re}_{L}^{1.22}-5.2}$

For Reynolds numbers above 1,600, the liquid film becomes turbulent and the Labuntsov correlation can be applied. The average value is given by [1]

$$
\alpha_{\mathrm{La}}=\mathrm{Co} \frac{\operatorname{Re}_{L}}{8570+58 \operatorname{Pr}_{L}^{-0.5}\left(\operatorname{Re}_{L}^{0.75}-253\right)}
$$

A plot of these three models is given in Figure 1. For practical use, asymptotic models are often introduced in order to take into account laminar, wavy film, and turbulent film condensation simultaneously (Figure 2):

$$
\begin{aligned}
& \alpha_{\mathrm{LW}}=\left(\alpha_{\mathrm{Nu}}^{2}+\alpha_{\mathrm{Ku}}^{2}\right)^{0.5} \\
& \alpha_{\mathrm{WT}}=\left(\alpha_{\mathrm{Ku}}^{2}+\alpha_{\mathrm{La}}^{2}\right)^{0.5}
\end{aligned}
$$

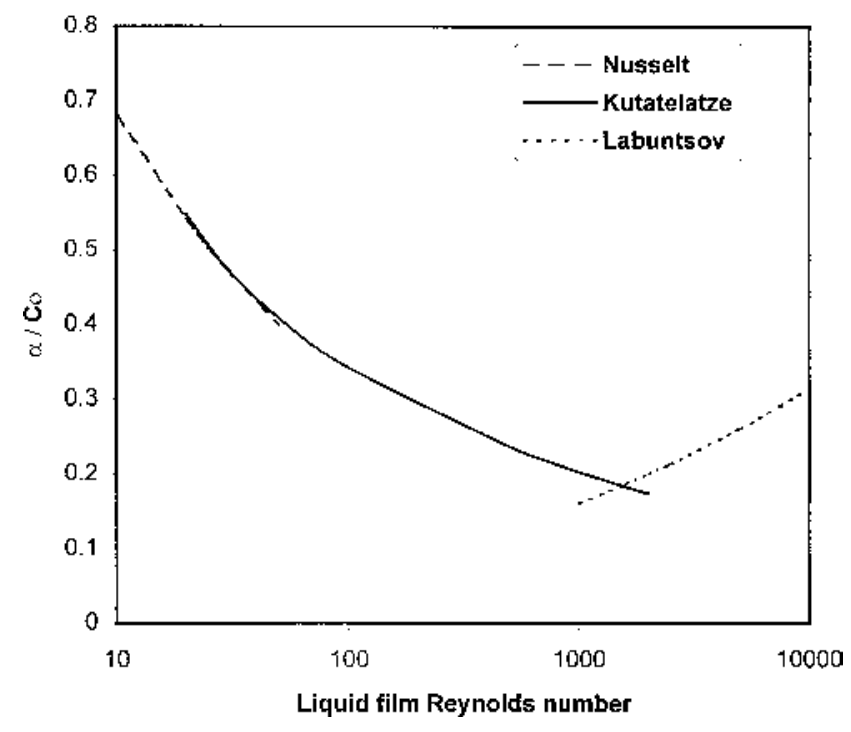

Figure 1 Filmwise condensation models. 


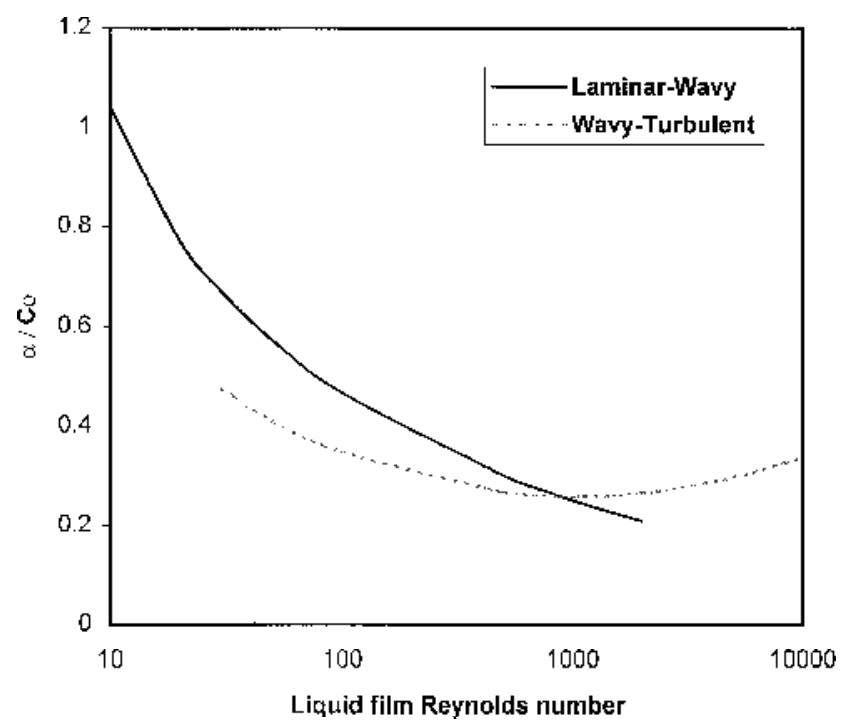

Figure 2 Asymptotic models for filmwise condensation.

\section{Forced-Convection Regime}

In the shear-controlled regime, several theoretical or semiempirical correlations exist for predicting the heat transfer coefficient. The most common ones are the Akers correlation modified by Cavallini and Zecchin (as presented by Cavallini et al. [2]), the Boyko-Kruzhilin [3], and the Shah [4] correlations.

Akers or Cavallini-Zecchin :

$\alpha_{\mathrm{cv}}=a \operatorname{Re}_{\mathrm{eq}}^{b} \operatorname{Pr}_{L}^{0.33} \frac{\lambda_{L}}{D_{h}}$

where $\mathrm{Re}_{\mathrm{eq}}$ is an equivalent Reynolds number for the liquid + vapor mixture:

$\operatorname{Re}_{\mathrm{eq}}=\frac{\dot{m}\left[(1-x)+x\left(\rho_{L} / \rho_{G}\right)^{0.5}\right] D_{h}}{\mu_{L}}$

Boyko and Kruzhilin or Shah:

$\alpha_{\mathrm{cv}}=\alpha_{\mathrm{LO}} F$

where the heat transfer coefficient of the liquid phase $\left(\alpha_{\mathrm{LO}}\right)$ is deduced from specific correlations for forced convection and $F$ is the enhancement factor.

\section{CONDENSATION IN PLATE HEAT EXCHANGERS}

\section{Steam Condensation}

Tovazhnyanski and Kapustenko [5] have performed some tests on a plate heat exchanger with a $60^{\circ}$ corrugation angle. Their tests covered a large range of Reynolds numbers. For Reynolds numbers above 300, a shear- controlled regime dominates and the heat transfer coefficients are compared to a modified Boyko and Kruzhilin correlation, the Boyko-Kruzhilin enhancement factor being

$F=\left[1+x\left(\frac{\rho_{L}}{\rho_{G}}-1\right)\right]^{0.5}$

The use of this correlation means that the enhancement of the heat transfer coefficients in condensation is comparable to the enhancement in single-phase flows. For example, for a $60^{\circ}$ corrugation angle, the heat transfer coefficient is six times larger than for a comparable plain channel (Thonon et al. [6]). For lower Reynolds numbers $\left(\operatorname{Re}_{L}<300\right)$, condensation seems to be gravitycontrolled. However, the Nusselt law underestimates the heat transfer coefficient. The herringbone pattern of the corrugation tends to drain the condensate to the periphery of the channel and keeps the condensate film thin.

Di-an et al. [7] have studied steam condensation in two different geometries: a plain rectangular channel and a corrugated channel $\left(45^{\circ}\right.$ corrugation angle). For the plain rectangular channel with Reynolds numbers between 70 and 500, the Nusselt theory predicts the heat transfer coefficients with good accuracy. For the corrugated channels, their results clearly outline the two regimes of condensation. For Reynolds numbers below 350 a gravity-controlle d regime exists, and for Reynolds numbers above 350 a shear-controlle d regime dominates. The change of regime at a Reynolds number of 350 is explained by the change in the flow pattern. In corrugated channels, the transition from laminar to turbulent regime occurs at a lower Reynolds number than for a plain tube (about $\mathrm{Re}_{L}=400$ ). The intensification compared to the plain channel is $60 \%$ at a Reynolds 
number of 250 and of $220 \%$ for a Reynolds number of 900.

Wang and Zao [8] studied steam condensation in a plate heat exchanger with a $45^{\circ}$ corrugation angle. Their results clearly indicate that the heat transfer coefficient is shear-controlled: the heat transfer coefficient increases with the liquid film Reynolds number. The intensification of the heat transfer coefficient compared to the Nusselt theory varies from a factor of 2 to 3 depending on the flow conditions.

Wang et al. $[9,10]$ have studied steam condensation in one plate and frame and two brazed heat exchangers. The effect of mass flux and pressure has been studied. The results have been compared to the Shah and BoykoKruzhilin correlations and a large discrepancy has been observed. The density exponent of the Boyko-Kruzhilin correlation has been reduced to 0.45 and allows better predictive accuracy.

\section{Condensation of Refrigerants}

Compact heat exchangers are often used in refrigerant systems. A review has been recently presented by Palm and Thonon [11].

For ammonia applications, Panchal and Rabas [12] have carried out two series of tests with high and low corrugation angle $\left(60^{\circ}\right.$ and $\left.30^{\circ}\right)$. The results indicate that the plates with low corrugation angle give higher heat transfer coefficients than the plates with a $60^{\circ}$ corrugation angle. This is probably caused by an increase of the liquid hold-up in high-corrugation-angle plates.

Kumar [13] has reported results for condensation of R22 and ammonia in various types of plate heat exchangers. The results indicate that the condensation is gravity-controlled for low Reynolds numbers, and shear-controlled for higher Reynolds number. The measured heat transfer coefficients are 1.5 to 4 times larger than those expected in a comparable plain tube. The same type of results was also obtained by Navarro and Bailly [14], for condensation of refrigerants in compact brazed heat exchangers.

Chopard et al. [15] have performed tests for condensation of R22 at high Reynolds numbers in welded plate heat exchangers. Three different geometries were tested (plain rectangular, in-line, or staggered studs). The results are presented in terms of an intensification factor of the single-phase heat transfer coefficient. The heat transfer coefficients of in-line or staggered studs are significantly higher than those of the plain channel. Furthermore, even for the plain channel, the Shah correlation underestimates the heat transfer coefficients. Local measurements of the void fraction have shown that the liquid is drained to the periphery and that a thin film of liquid remains in the central part of the channel (Figure 3).

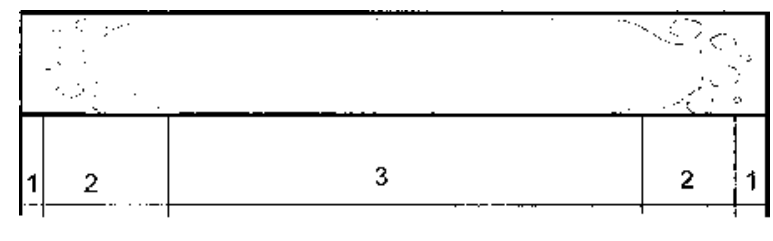

1 : Liquid rich area 2 : Churn flow $3:$ Annular flow

Figure 3 Flow structure in a rectangular channel.

Arman and Rabas [16] made a serious effort to develop a general computer program for heat transfer and pressure drop of single-component and binary mixtures during condensation in plate heat exchangers. Starting with a review of the sparse literature in the area, they conclude that the condensation heat transfer is shearcontrolled. The computation scheme for heat transfer was based on a correlation by Tovazhnyanski and Kapustenko [5] and for pressure drop on the LockhartMartinelli method. The condensation channel is divided into a number of steps, and the local heat transfer coefficient and pressure drop of each step is calculated iteratively. A number of constants in the correlations were determined by comparison with experimental data from the literature. Results from new experiments with pure saturated ammonia were then compared to the predictions of the computer program, and the deviations were shown to be small for the case of single-componen $t$ fluids.

More recently, Yan et al. [17] have presented results on condensation of R134a in a compact brazed heat exchanger having a $60^{\circ}$ corrugation angle. The effects of mass flux, average heat flux, local vapor quality, and operating pressure have been studied. The results indicate that the heat transfer coefficient increases with mass flux, indicating forced-convection heat transfer. To correlate the results a modified Akers correlation is proposed:

$\mathrm{Nu}=a \operatorname{Re}_{\mathrm{eq}}^{b} \operatorname{Pr}_{L}^{1 / 3}$

As outlined by Srinivasan and Shah [18], the heat transfer performances are closely linked to the flow pattern. Most of the conventional in-tube correlations fail in predicting the heat transfer coefficient in compact heat exchangers, as the flow patterns are radically different from in-tube flows. Furthermore, for very small channels, the surface tension has to be taken into account.

\section{EXPERIMENTAL APPARATUS}

\section{General Description}

A test rig devoted to hydrocarbon applications has been used for the experiments. Fluids such as 


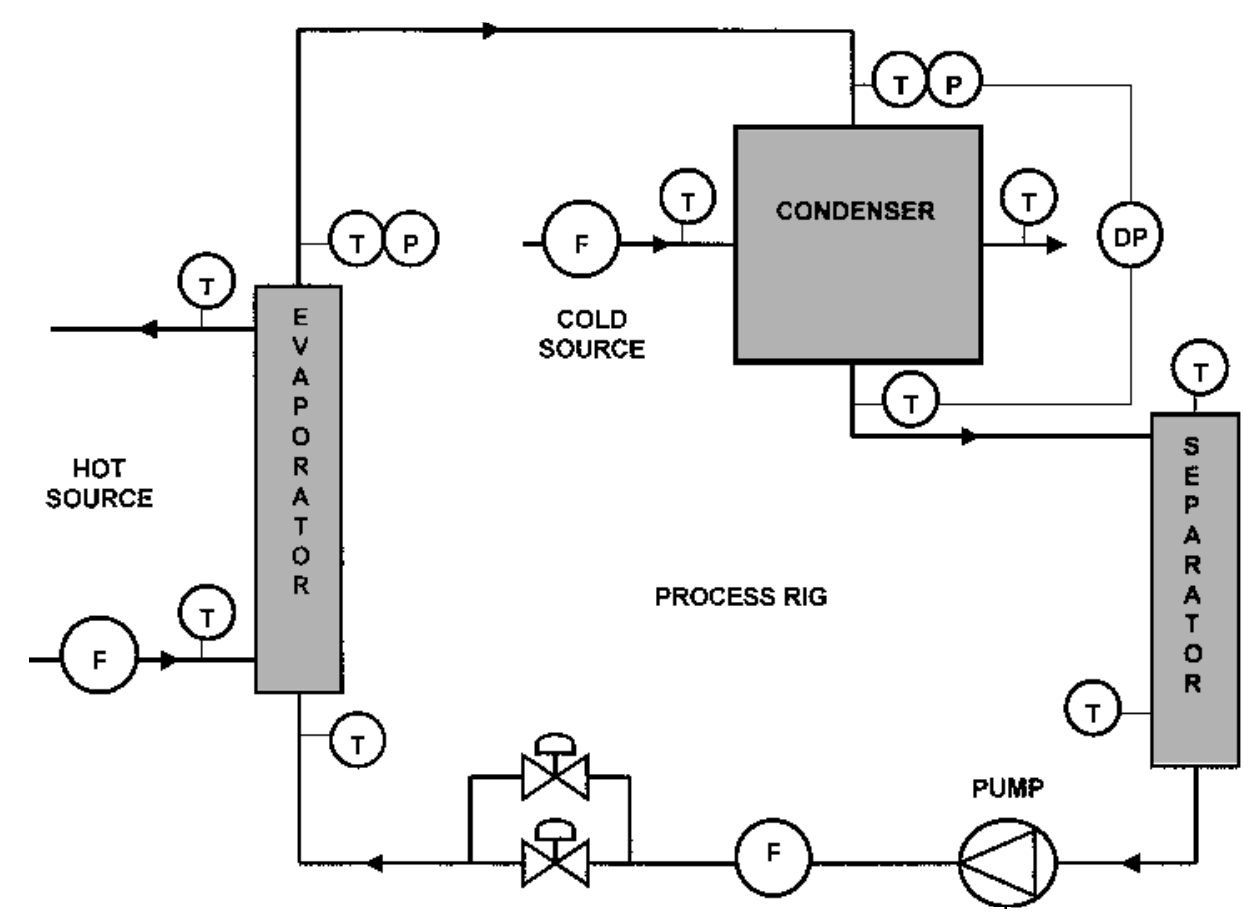

Figure 4 Description of the hydrocarbon test rig. T, temperature measurement; P, pressure measurement; DP, drop pressure measurement; F, flow meter.

butane, propane, or mixtures can be used. The heat exchangers tested can be either evaporators or condensers. The pressure can be varied up to 20 bar with temperature up to $80^{\circ} \mathrm{C}$. The hydrocarbon flow rate is up to $600 \mathrm{~kg} / \mathrm{h}$ with a maximum heat duty of $70 \mathrm{~kW}$.

The test rig has three independent circuits (Figure 4):

The hot water circuit (100)

The cold water circuit (200)

The hydrocarbon circuit (300)

The condenser is installed after the evaporator and is fed by saturated vapor. The saturation conditions are checked by measurement of the inlet pressure and temperature and by comparison with the saturation curve of the fluid $\left[\mathrm{T}=f\left(p_{\text {sat }}\right)\right]$. At the heat exchanger outlet, the liquid flows directly to a storage tank. Consequently, the fluid temperature is assumed to be close to the saturation temperature, therefore neglecting possible subcooling of the liquid.

\section{Heat Exchanger Geometry}

The plate arrangement of the tested heat exchanger is given in Figure 5. The main characteristics are plate width, $B=0.3 \mathrm{~m}$; plate length, $L=0.3 \mathrm{~m}$; Corrugation angle, $45^{\circ}$; plate spacing, $e=0.005 \mathrm{~m}$; hydraulic diameter, $D_{h}=2 e=0.01 \mathrm{~m}$.

\section{Measurements}

The temperatures and pressures are measured on both the hydrocarbon and the water sides:

$T_{\text {in 300 }}$ : inlet hydrocarbon temperature, ${ }^{\circ} \mathrm{C}$

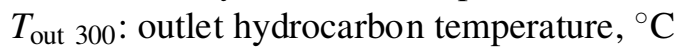

$P_{\text {in 300: }}$ inlet hydrocarbon pressure, bar

$\Delta P_{300}$ : hydrocarbon pressure drop, mbar

$\dot{M}_{300}$ : hydrocarbon mass flow rate, $\mathrm{kg} / \mathrm{s}$

$T_{\text {in 200 }}$ : inlet water temperature, ${ }^{\circ} \mathrm{C}$

$T_{\text {out 200 }}$ : outlet water temperature, ${ }^{\circ} \mathrm{C}$

$\dot{V}_{200}$ : water volumetric flow rate, $\mathrm{m}^{3} / \mathrm{s}$

The accuracy of the temperature measurements (after calibration ) is $\pm 0.2^{\circ} \mathrm{C}$. The flowmeters have an accuracy of $\pm 1 \%$. The differential and absolute pressure taps are

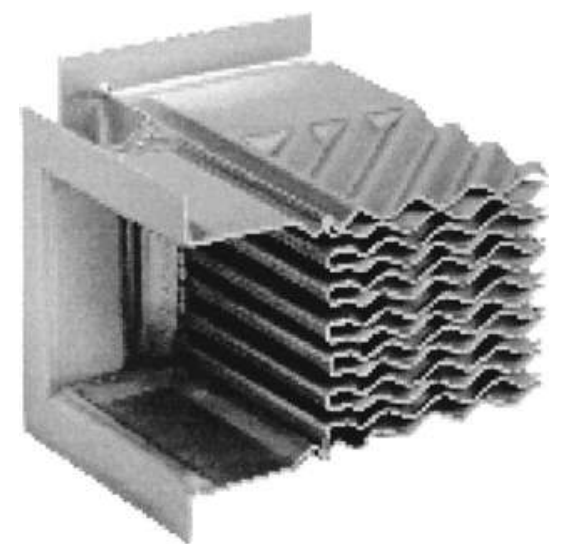

Figure 5 Detail of the compact heat exchanger. (courtesy of AlfaLaval Vicarb.) 
heated to avoid the presence of liquid in the connecting pipes, and the accuracy is $\pm 1 \%$.

\section{RESULTS}

\section{Data Reduction}

Experimental differences have been observed between the heat duties calculated on the water and hydrocarbon sides. These differences are mainly due to fluctuations on the hydrocarbon mass flow rate. The hydrocarbon mass flow meter is located between two tanks, and at low flow rates (or low heat duties) instabilities are measured by the flow meter. For heat duties greater than $20 \mathrm{~kW}$, the energy balance is within $\pm 10 \%$, which is acceptable for such two-phase flow experiments.

Therefore, the actual heat duty is assumed to be the one measured on the water side:

$\dot{Q}=\dot{Q}_{\text {water }}=\dot{V}_{200} \rho_{200} c_{p, 200}\left(T_{\text {out }, 200}-T_{\text {in, } 200}\right)$

Then, from this value and assuming an exact heat balance, the hydrocarbon mass flow rate is recalculated from

$\dot{M}_{300}=\frac{\dot{Q}_{\text {water }}}{\left(h_{\text {in }}-h_{\text {out }}\right)_{300}}$

The heat transfer coefficient on the condensation side is deduced from the overall heat transfer coefficient, where the heat duty is estimated from the water side:

$U=\frac{\dot{Q}}{\Delta T_{\ln } \cdot A}$

The average heat transfer coefficient on the condensation side is deduced from

$\frac{1}{U}=\frac{1}{\alpha_{1}}+R_{w}+\frac{1}{\alpha_{2}}$

where $\alpha_{1}$ and $\alpha_{2}$ are the heat transfer coefficients on the hydrocarbon and water sides. The latter is calculated with the correlations presented by Thonon et al. [6] obtained for several plate heat exchangers. For the geometry studied (corrugation angle of $45^{\circ}$ ), the correlation is

$\mathrm{Nu}=0.347 \mathrm{Re}^{0.653} \operatorname{Pr}^{0.33}$

where the Reynolds and Prandtl numbers are calculated for the single-phase liquid flow on the cooling side.
The reference heat transfer surface $(A)$ is based on the projected area. Therefore, the surface extension (less than 20\%) is included directly in the heat transfer correlation.

The results concerning the heat transfer coefficients are presented using the liquid Reynolds number assuming all the flow is liquid (condenser outlet):

$\operatorname{Re}_{\mathrm{LO}}=\frac{\dot{m} D_{h}}{\mu_{L}}$

where $\dot{m}$ is the mass velocity of the hydrocarbon flow.

The estimated uncertainty for the heat transfer coefficient on the condensation side ranges between $15 \%$ at high Reynolds number and 30\% at low Reynolds numbers.

\section{Tests Performed}

Five sets of tests have been performed: three with pure fluids and two with mixtures. For each fluid, the absolute pressure and the mass flow rate on the condensation side were varied. The range covered is presented in Figure 6 for pentane, butane, propane, butane-propane ( $49 \%-51 \%$ by mass), and butane-propane $(28 \%-72 \%$ by mass).

The pure fluids used are of high quality and contain less than $0.1 \%$ of other components. The physical properties have been calculated using the Prophy software developed by PROSIM. For the two butane + propane mixtures, the mass concentration has been estimated by measuring the dew and bubble temperatures at different pressures and by comparing with the temperature predicted by the physical property software.

\section{Pure Fluid Condensation}

Three series of tests have been performed using pure hydrocarbons (pentane, butane, and propane) and the overall thermal and hydraulic performances have been recorded and are presented in Figures 7-9. The operating pressure ranges from 1.5 up to 18 bar, with Reynolds numbers between 100 and 2,000.

The results clearly indicate that for low Reynolds numbers the heat transfer coefficient in condensation is similar to that of a laminar falling film and for higher Reynolds numbers turbulent effects tend to increase the heat transfer coefficient. The transition between these two mechanisms occurs for Reynolds numbers between 100 and 1,000, depending on the pressure.

The operating pressure has two effects. First, in the laminar zone, the heat transfer coefficients increase with pressure, which is essentially an effect of the physical properties. Second, the higher pressures give higher 


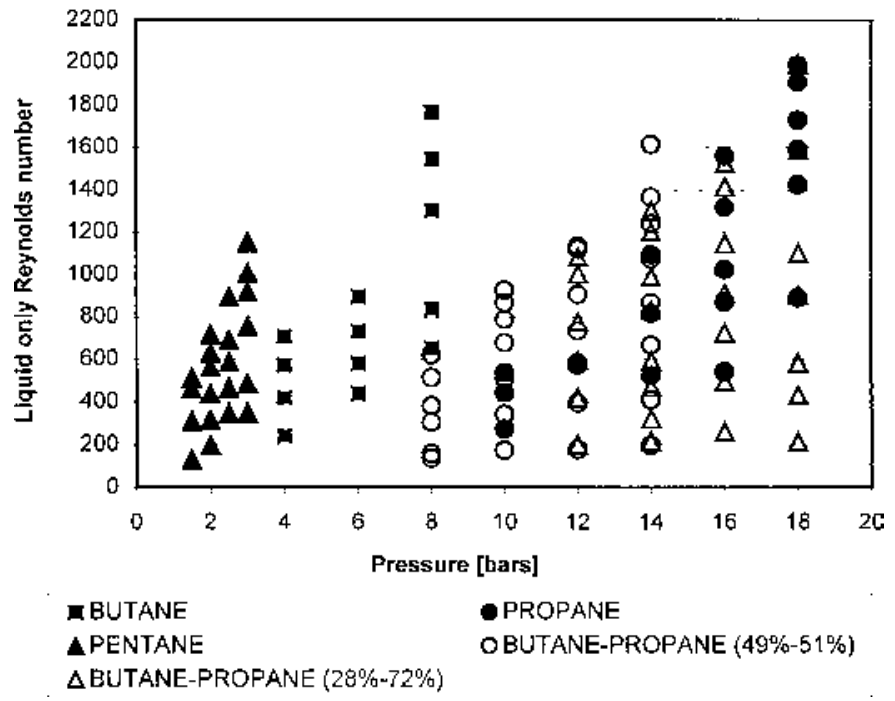

Figure 6 Experimental conditions (all data).

transition Reynolds numbers, and this might be linked to an effect of the condensate Prandtl number.

\section{Mixture Condensation}

For the mixtures (Figures 10 and 11), the behavior is quite different. In the first zone, the heat transfer coefficient increases with the Reynolds number, and then in the second zone the behavior is similar to the one of pure fluids.
These observation s outline the effect of mass transfer on the overall heat transfer coefficient. For low Reynolds numbers (laminar film) and for pure fluids the heat transfer resistance is mainly in the liquid film, and this resistance increases with the Reynolds number (Nusselt theory). For higher Reynolds numbers, the liquid film becomes turbulent and with increasing Reynolds numbers the heat transfer coefficient increases.

For pure fluids there is no mass transfer effect during condensation. On the contrary, with a mixture, there is

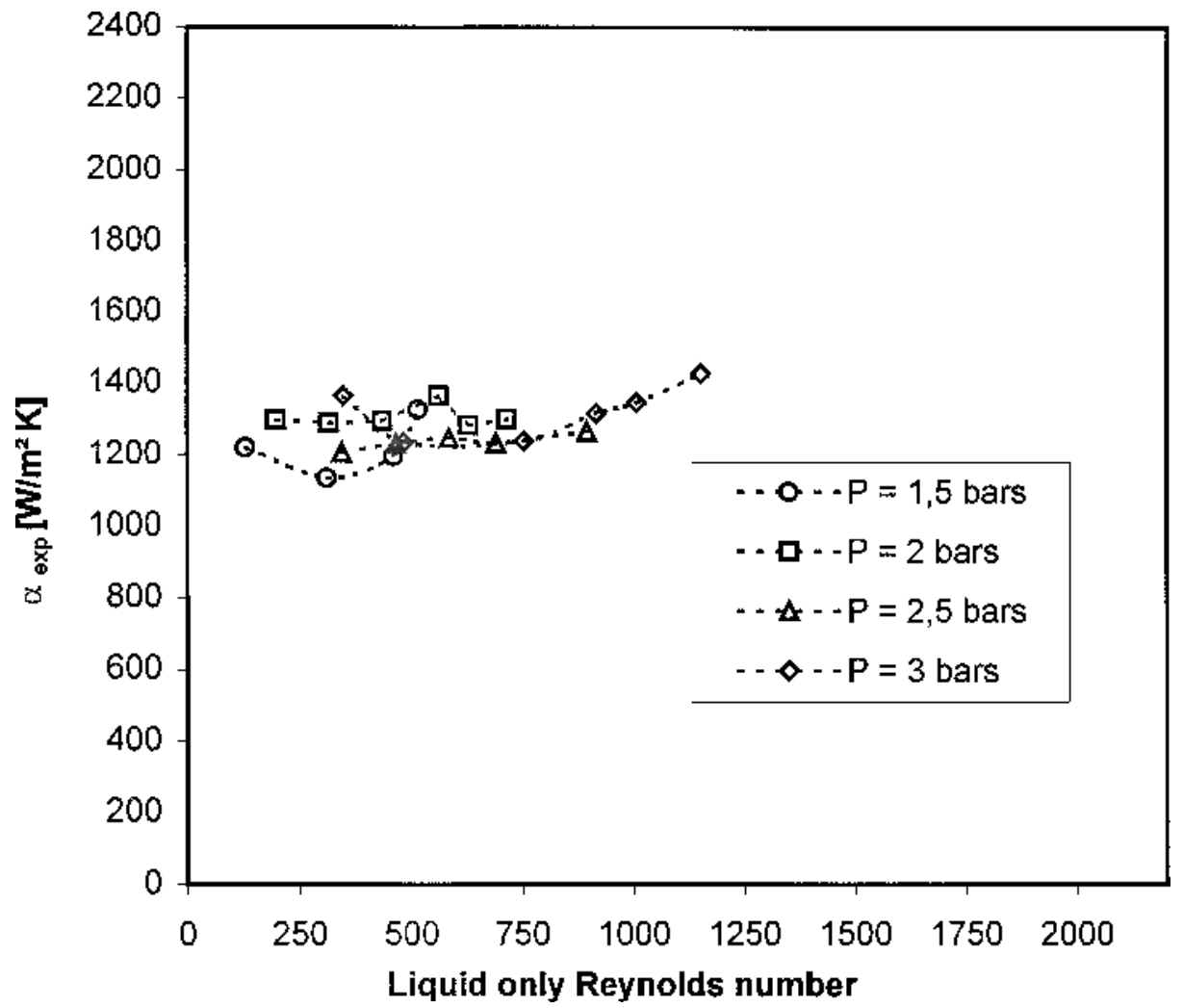

Figure 7 Condensation of pure pentane. 


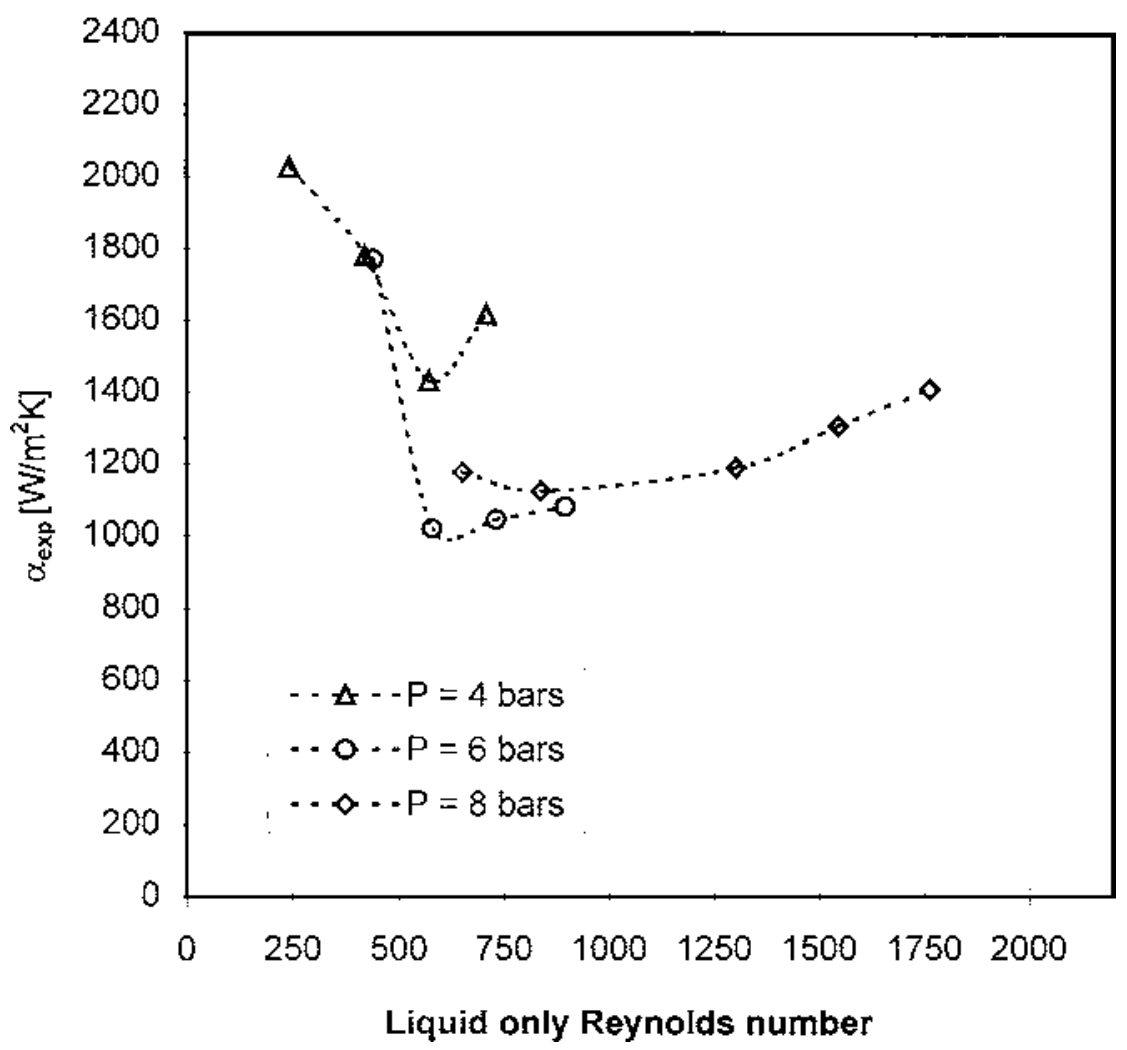

Figure 8 Condensation of pure butane.

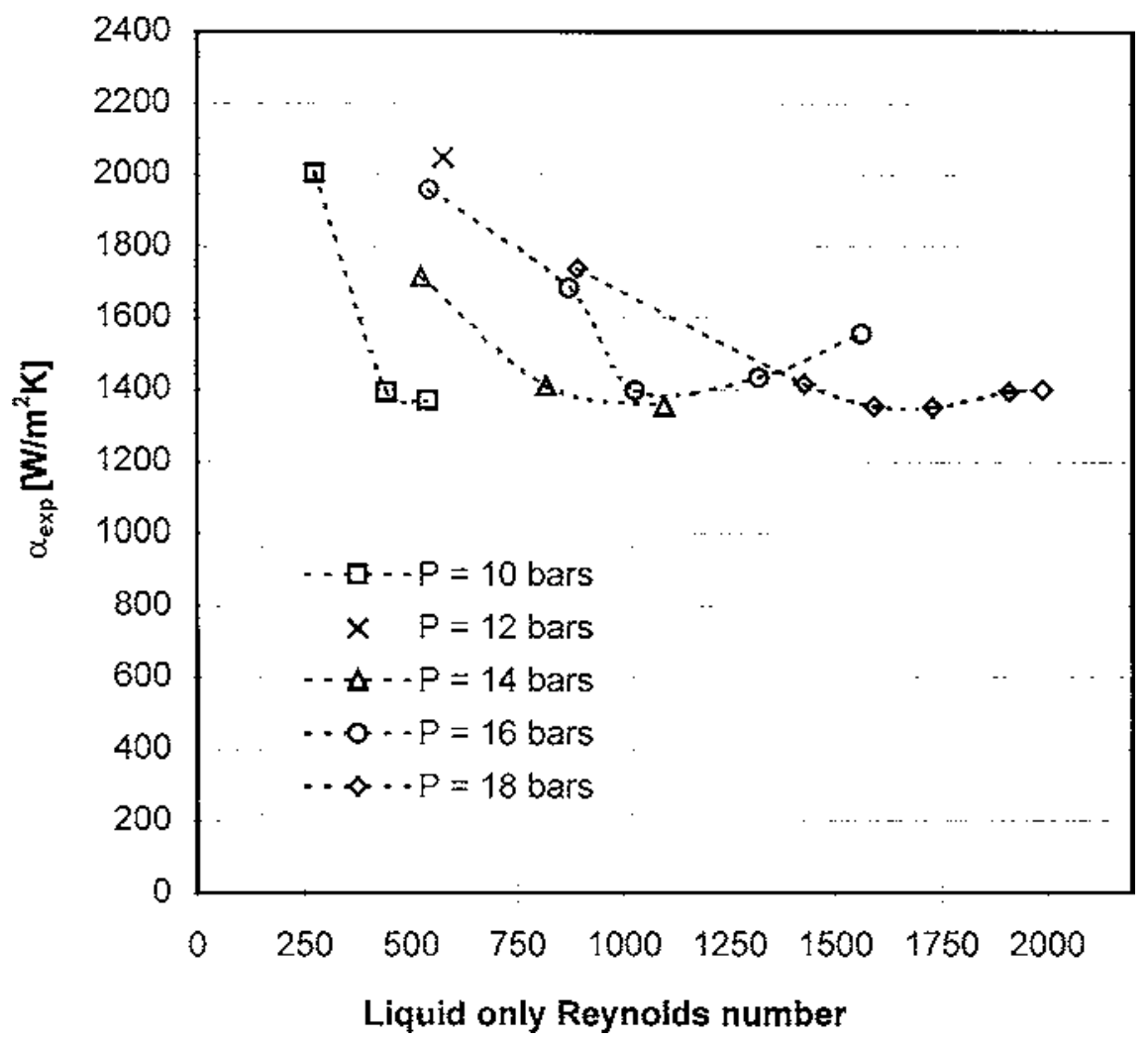

Figure 9 Condensation of pure propane. 


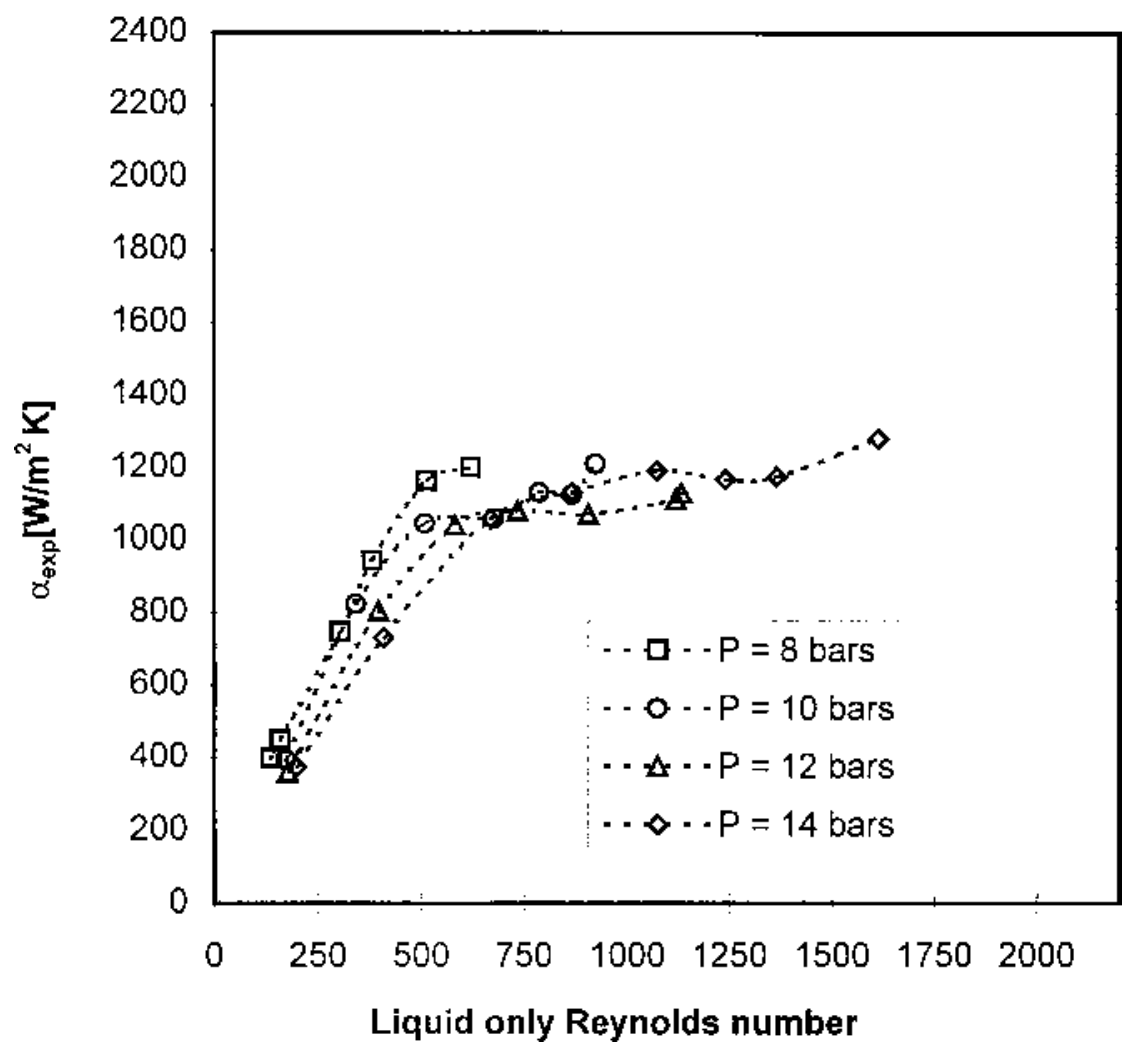

Figure 10 Condensation of a $49 \%-51 \%$ butane-propane mixture.

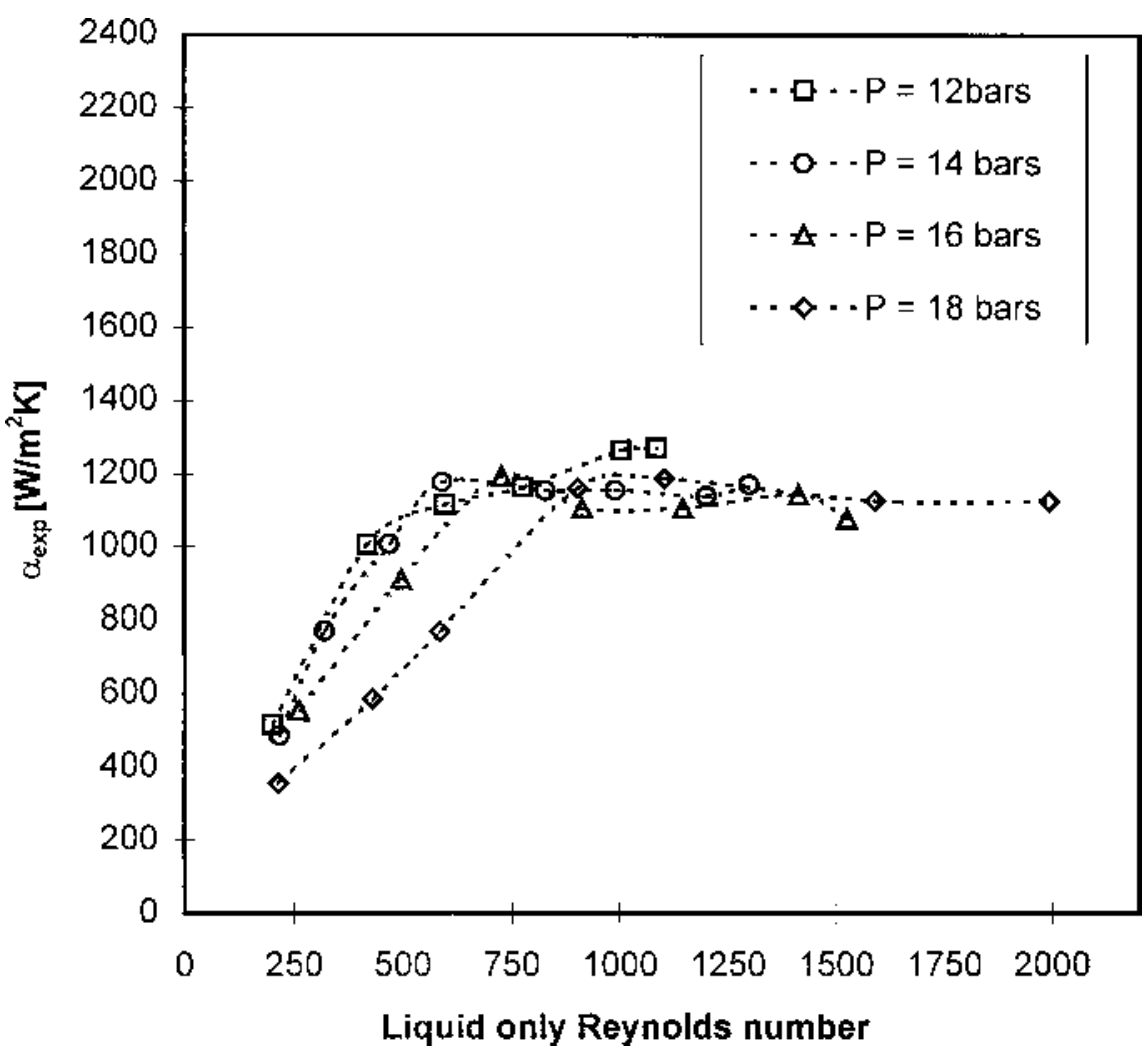

Figure 11 Condensation of a $28 \%-72 \%$ butane-propane mixture. 
a mass transfer resistance due to molecular diffusion in the gas phase. For low Reynolds numbers, the velocity is low and there is almost no mixing in the gas phase, consequently mass transfer effects will reduce the heat transfer coefficient. For higher Reynolds numbers, mixing occurs in the gas phase and enhances mass transfer; consequently the heat transfer resistance is mainly in the liquid film and the mixture behaves as a pure fluid.

\section{DATA ANALYSIS}

\section{Pure Fluids}

To correlate the results, two approaches can be adopted. We can consider either falling-film or forcedconvection correlations. For falling-film models, the heat transfer coefficients are plotted introducing the physical property number Co. For forced convection, the enhancement factor $F$ is used [Eq. (10)]. The data have been compared to several correlation s for filmwise (Figure 12) and in-tube forced convection (Figure 13) condensation, but all these correlations fail in predicting the heat transfer performances. In the laminar regime, condensate drainage may occur in the furrow of the corrugation, and this will reduce the mean film thickness and consequently increase heat transfer. The vapor velocity at the heat exchanger inlet is relatively low and the shear effect should be negligible.

A new correlation is proposed and adjusted based on the measurements. This correlation is based on film condensation and introduces a corrective term taking into account the geometry of the corrugated channel. The effect of the geometry is introduced by the heat transfer coefficient of the liquid phase $\left(\alpha_{\mathrm{LO}}\right)$. The use of the equivalent Reynolds number $\left(\mathrm{Re}_{\mathrm{eq}}\right)$ rather than the liquid Reynolds number $\left(\operatorname{Re}_{L}\right)$ gives better results (Figure 14).

$$
F=1564 \mathrm{Re}_{\mathrm{eq}}^{-0.76}=\frac{\alpha}{\alpha_{\mathrm{LO}}}
$$

This new correlation gives satisfactory results for the three pure fluids tested (Figure 15): $80 \%$ of the data are predicted within $\pm 20 \%$. The three pure fluids used (pentane, butane, and propane) have physical properties that are quite similar, and it is not surprising that a single correlation, based on a nondimensional approach, gives good results. To validate and generalize this correlation, other operating conditions (lower pressures) and more viscous fluids should be used. Only one geometry has been tested, but the correlation has been built with nondimensional numbers. The general form of this correlation (enhancement factor) is similar to the one proposed by Tovazhnyanski and Kapustenko [5].

\section{Mixture}

The experimental data (Figure 16) suggests two heat transfer mechanisms: (1) a laminar regime in which the mass transfer resistance is the dominant resistance;

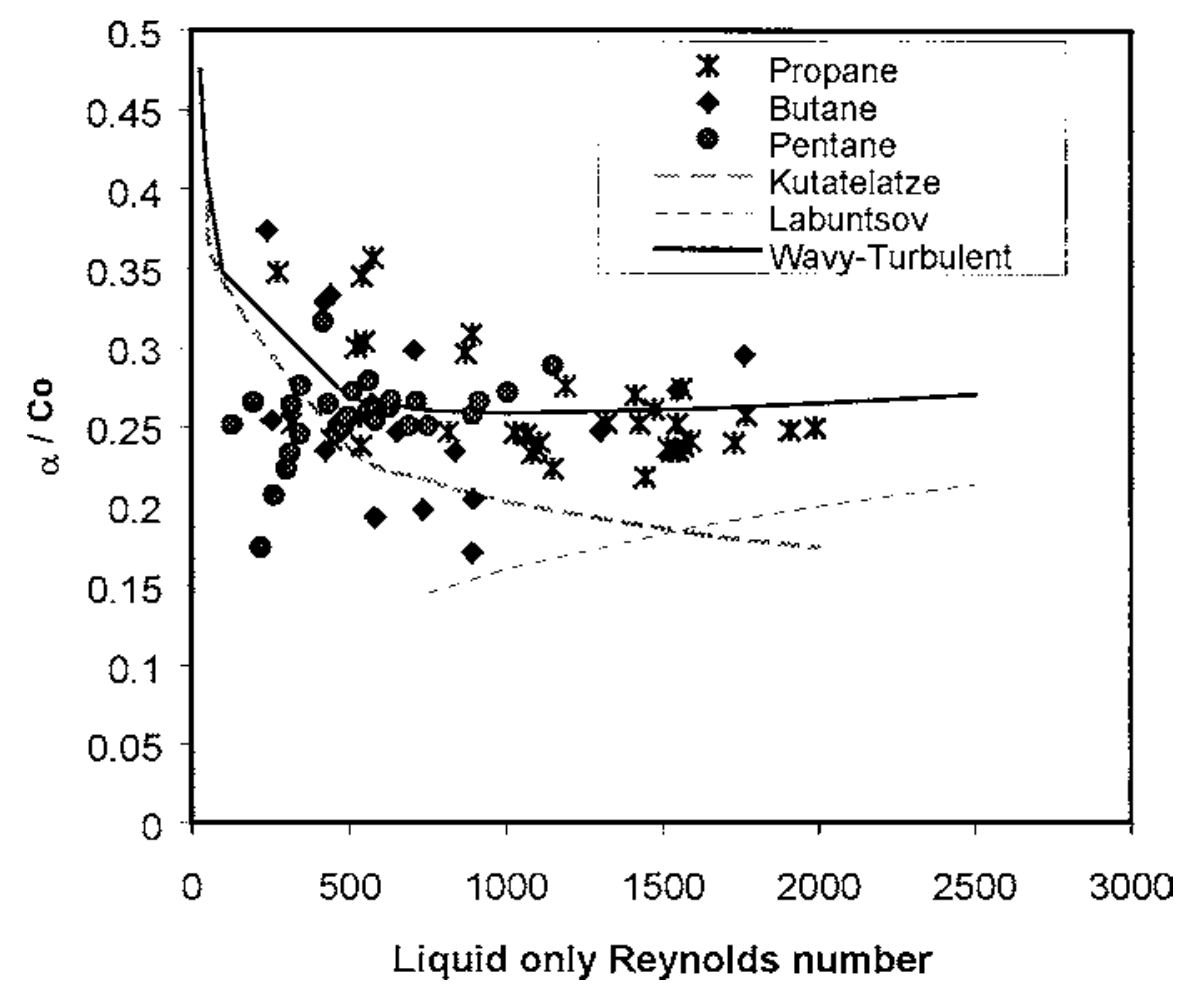

Figure 12 Comparison of measured heat transfer coeffi cient with fi lmwise condensation models. 


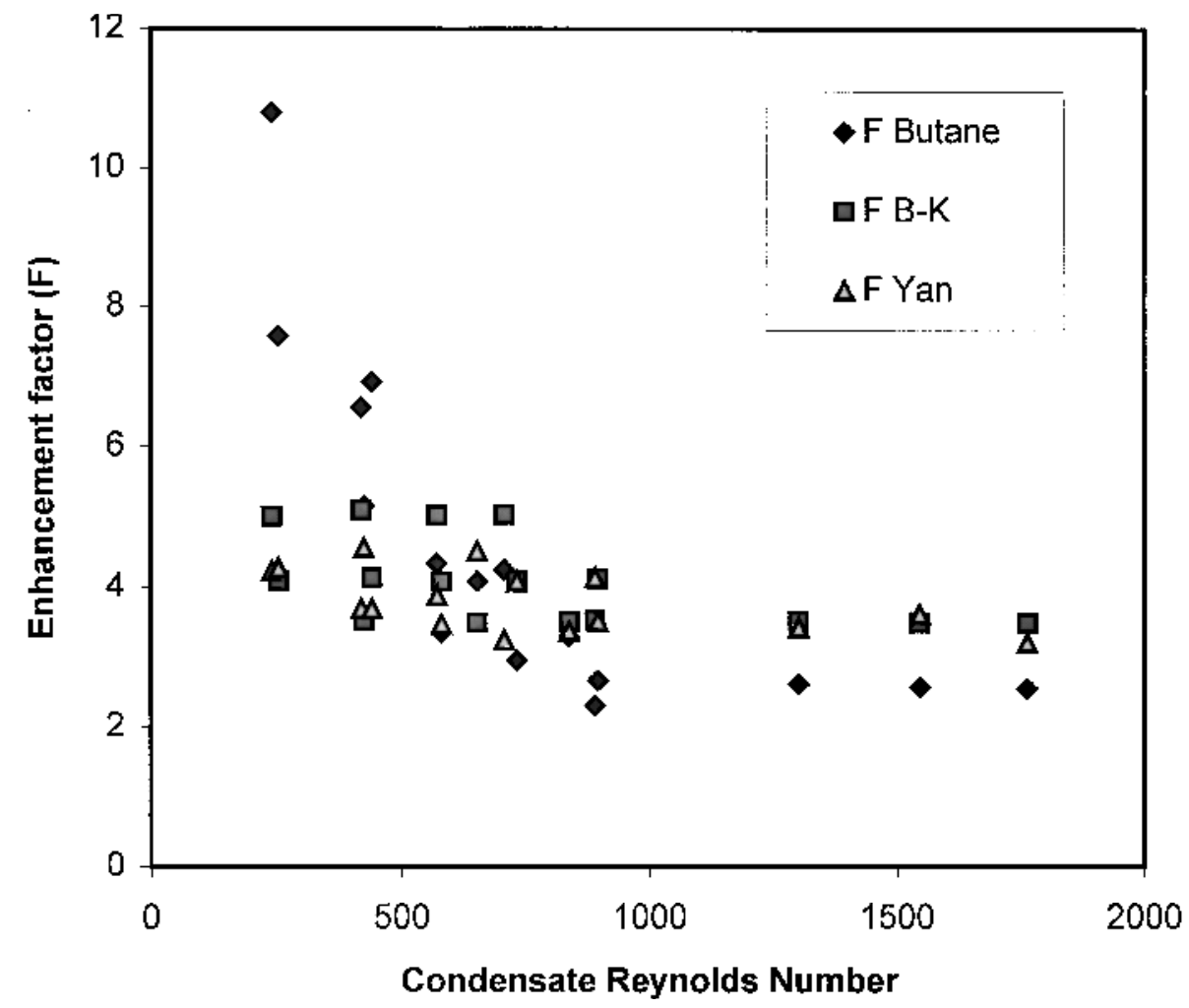

Figure 13 Comparison of condensation enhancement factors using butane with condensation correlations $\left(F_{\mathrm{B}-\mathrm{K}}\right.$, Boyko-Kruzhilin [3]; $F_{\text {Yan }}$, Yan et al. [17]).

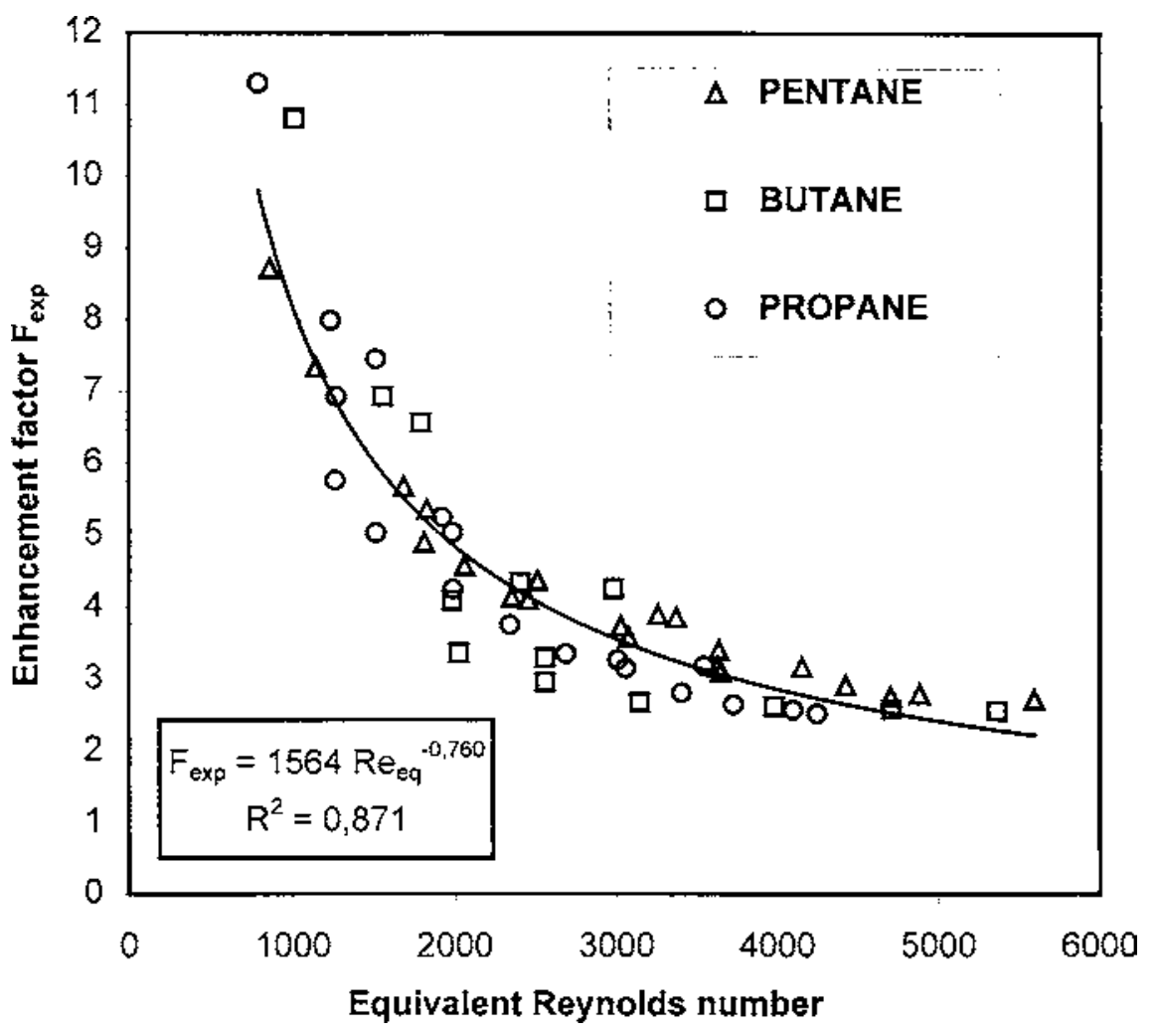

Figure 14 Condensation of pure fluids. 


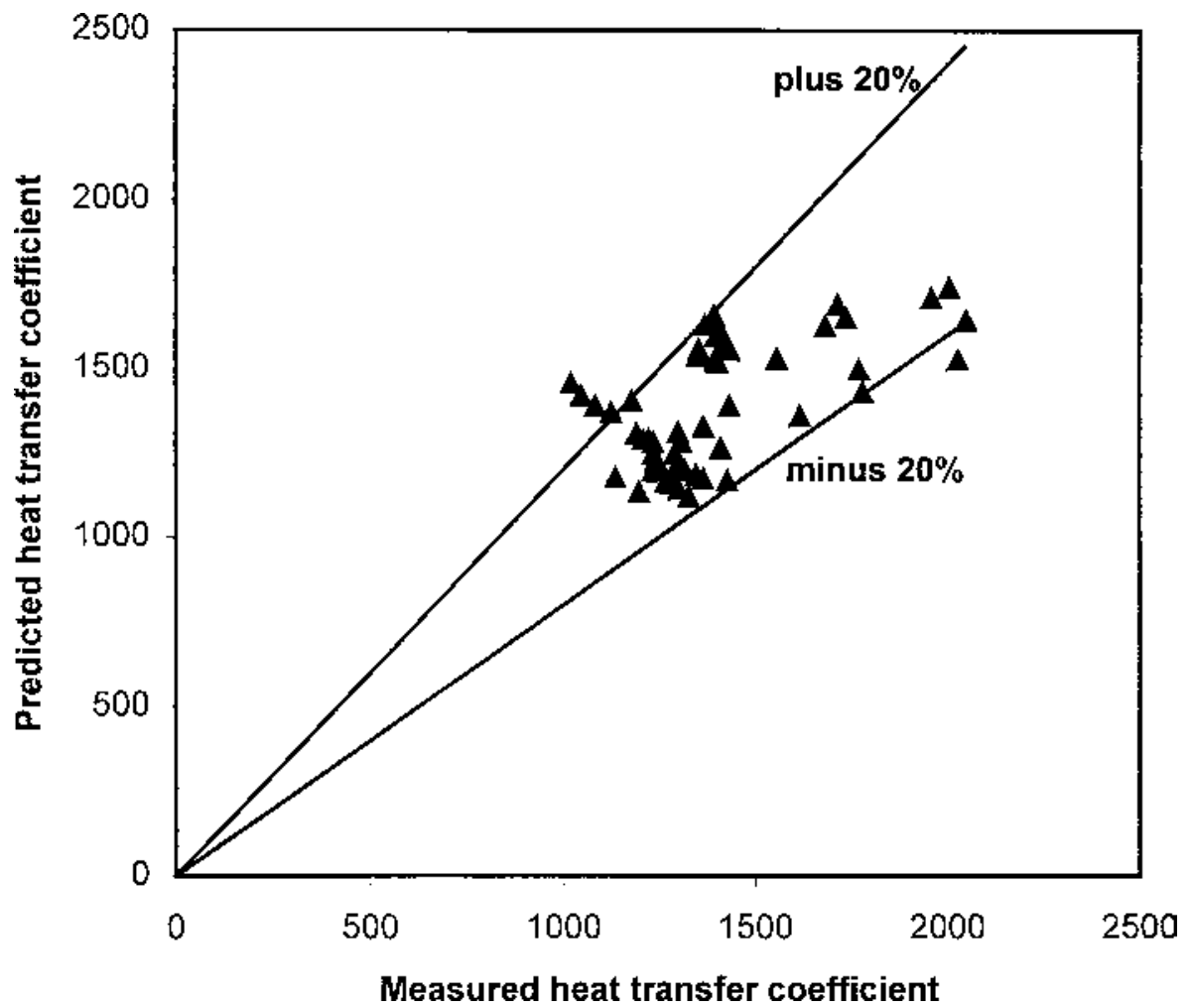

Figure 15 Comparison of predicted and measured heat transfer coefficients.

(2) a turbulent regime in which heat transfer is controlled by the liquid film.

The condensation curve method has been applied to our results. The mass transfer resistance is assumed to be proportional to the heat transfer resistance in the vapor phase $\left(1 / \alpha_{G}\right)$. A correction factor $(z)$ is introduced to take into account the concentration profile between the bulk of the flow and the liquid film interface. The

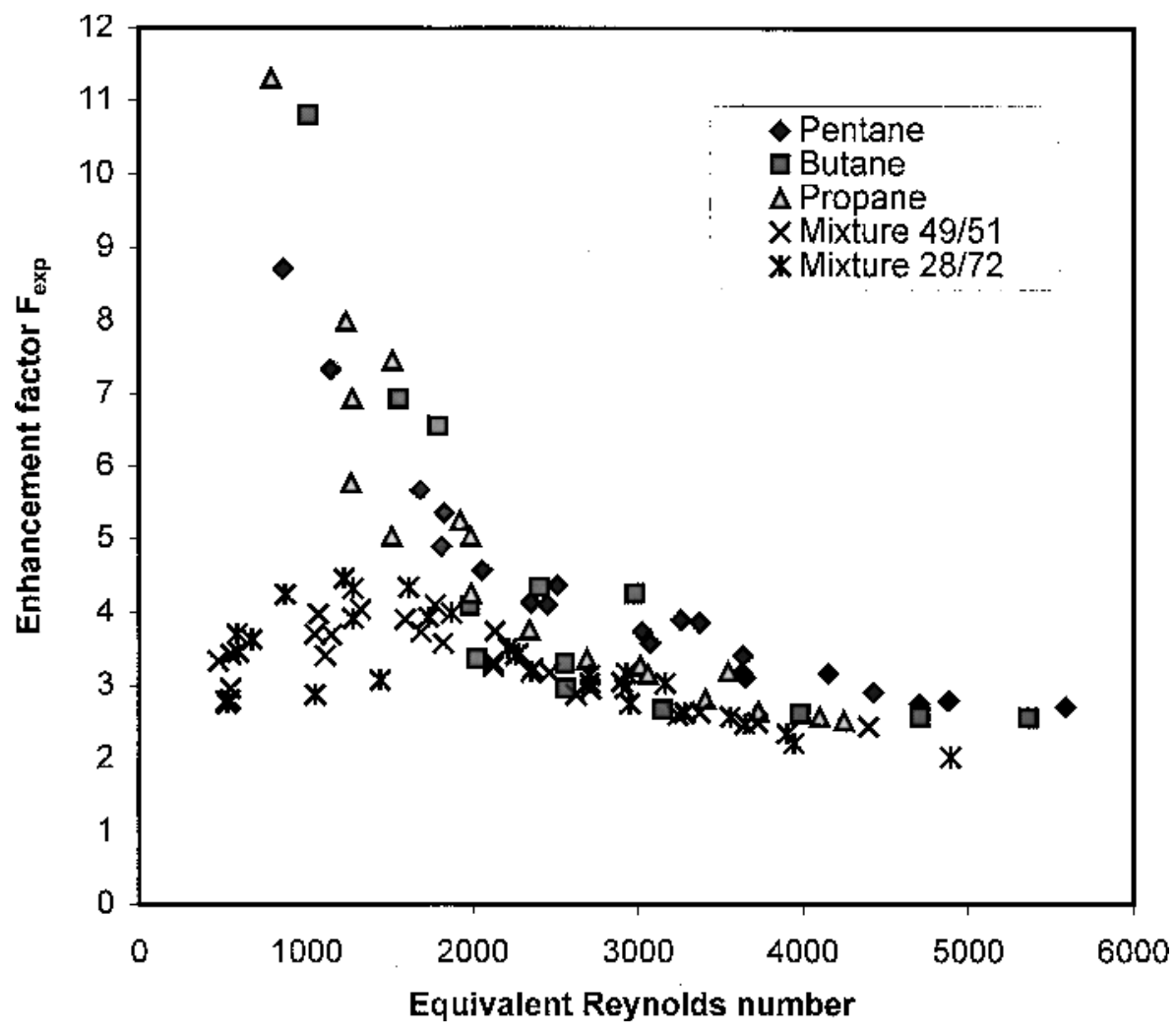

Figure 16 Enhancement factor for pure fl uids and mixtures. 


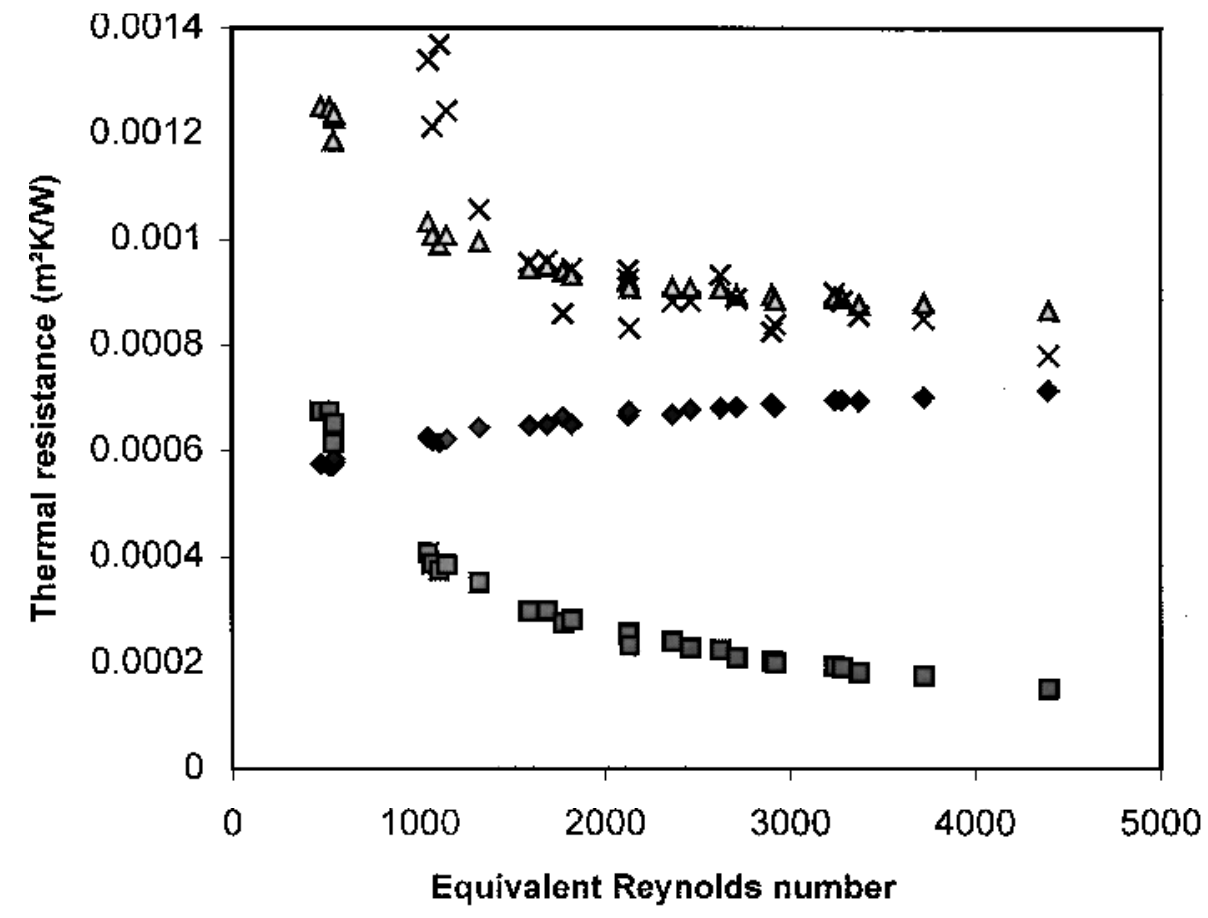

- Heat transfer resistance $\quad$ a Mass transfer resistance

$\Delta$ Overal! predicted resistance $\times$ Overall measured resistance

Figure 17 Evaluation of mass and heat transfer resistances.

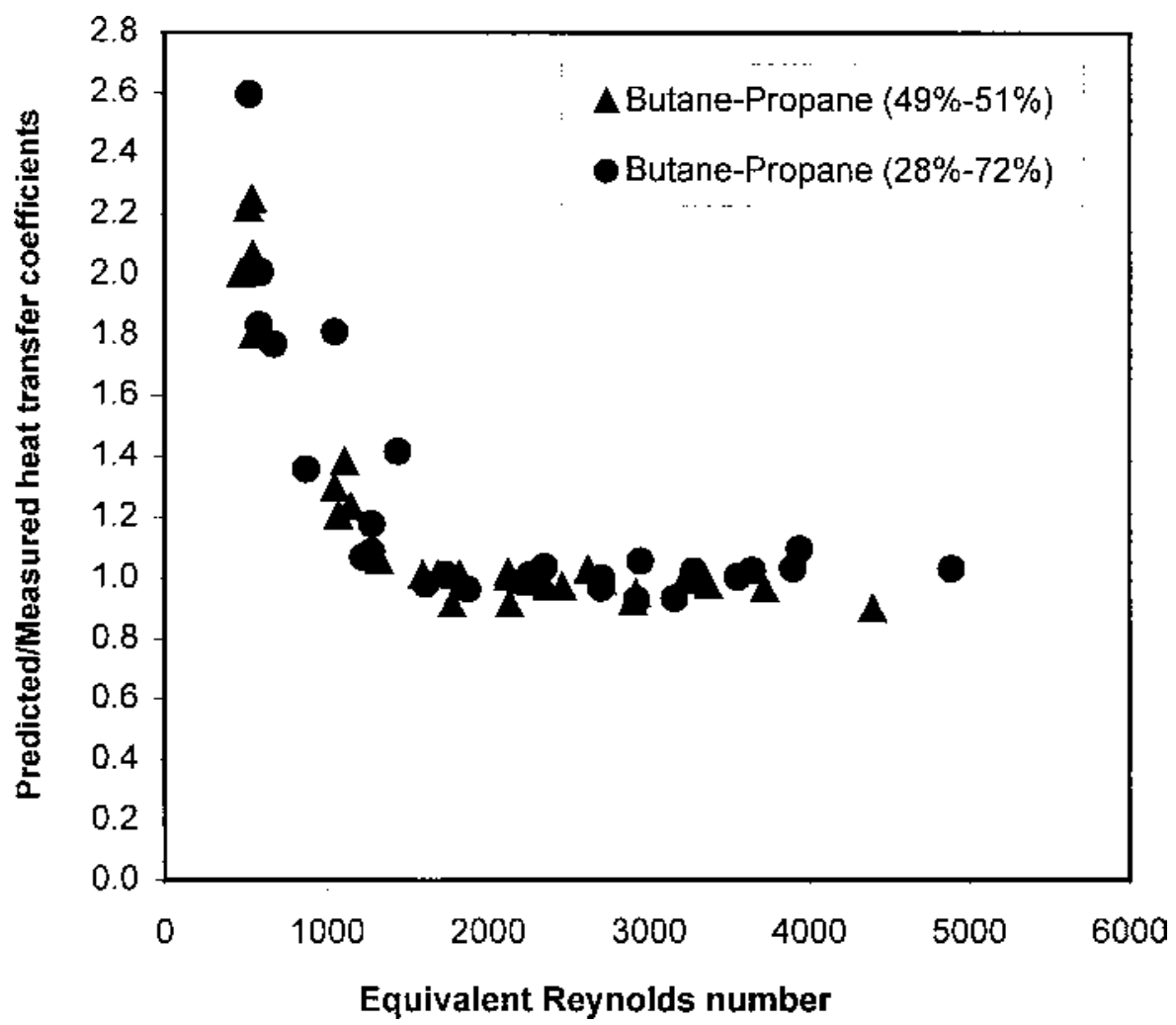

Figure 18 Condensation of mixtures. 
resulting heat transfer coefficient is given by Silver [19] or Bell and Ghaly [20]:

$$
\alpha=\frac{1}{\left(1 / \alpha_{\text {pure fluid condensation }}\right)+\left(z / \alpha_{G}\right)}
$$

where the vapor heat transfer coefficient is estimated from single-phase heat transfer correlation, calculating the Reynolds number with the vapor fraction; $z$ is given by

$$
z=x c_{p G} \frac{d T}{d h}
$$

where $d T / d h$ is the inverse of the slope of the condensation curve $h=h(T)$.

The calculation is carried out using an average vapor quality of $x=0.5$. The physical properties are estimated at the dew temperature for the vapor phase and at the bubble temperature for the liquid phase.

The results are presented in Figure 17. The equivalent mass transfer resistance decreases with the Reynolds number; on the contrary, the condensate heat transfer resistance increases. The experimental trends are well predicted by this model. For the turbulent regime ( $\mathrm{Re}>$ $1,500)$ there is very good agreement, but for the laminar regime the heat transfer coefficient is overpredicted (Figure 18).

\section{CONCLUSION}

A small industrial compact condenser has been installed and instrumented on a hydrocarbon test rig at GRETh. Five sets of tests have been performed using hydrocarbons: three with pure fluids and two with mixtures. The pressure was varied between 1.5 and 18 bar for a range of Reynolds numbers between 100 and 2,000. These condition s are representative for industrial cases.

For pure fluids (pentane, butane, and propane), two regimes have been identified. For low Reynolds numbers, the heat transfer coefficient in condensation decreases, indicating a laminar regime. For higher Reynolds numbers, the heat transfer coefficient increases gently, indicating a transition to turbulent flow.

For mixtures (butane + propane), the behavior is different. At low Reynolds numbers, the heat transfer coefficient is much lower than with pure fluids and increases with the Reynolds number. For higher Reynolds numbers, it remains almost constant or increases slightly, and the values are close to those obtained with pure fluids. Furthermore, a significant pressure effect is observed for the laminar regime: low pressures give higher heat transfer coefficients. These observations indicate that mass transfer effects are significant and affect heat transfer during condensation.
A model for pure fluid condensation has been established and gives satisfactory results within the range of tested fluids. For mixtures, the condensation curve method does not allow estimating the heat transfer coefficient in the laminar regime. But for turbulent regimes, as the mass transfer effect is negligible, the pure fluid model allows predicting the condensation heat transfer coefficient of mixtures.

In order to validate the measurements and the correlations, obtained on small-scale units, industrial measurements have been performed. A prototype compact heat exchanger has been designed and manufactured by Alfa-Laval Vicarb and installed in an industrial plant producing chloroform.

\section{NOMENCLATURE}

a constant

$A \quad$ heat transfer area, $\mathrm{m}^{2}$

$B$ plate width, $\mathrm{m}$

Co physical property number, $\mathrm{W} / \mathrm{m}^{2} \mathrm{~K}$

$c_{p}$ heat capacity, $\mathrm{J} / \mathrm{kg} \mathrm{K}$

$D_{h} \quad$ hydraulic diameter, $\mathrm{m}$

$e \quad$ plate spacing, $\mathrm{m}$

$F \quad$ enhancement factor

$g$ gravity, $\mathrm{m} / \mathrm{s}^{2}$

$h \quad$ specific enthalpy, $\mathrm{J} / \mathrm{kg}$

$L \quad$ length, $\mathrm{m}$

$\dot{M}$ mass flow rate, $\mathrm{kg} / \mathrm{s}$

$\dot{m} \quad$ mass velocity, $\mathrm{kg} / \mathrm{s} \mathrm{m}^{2}$

$\mathrm{Nu} \quad$ Nusselt number

$p$ pressure, $\mathrm{Pa}$

$P \quad$ perimeter, $\mathrm{m}$

Pr Prandtl number

$\dot{Q}$ heat duty, W

Re Reynolds number

$\mathrm{Re}_{\text {eq }}$ equivalent Reynolds number

$R_{w} \quad$ wall resistance, $\mathrm{m}^{2} \mathrm{~K} / \mathrm{W}$

$T$ temperature, ${ }^{\circ} \mathrm{C}$

$\Delta T_{\text {ln }} \quad$ log mean temperature difference, $\mathrm{K}$

$U$ overall heat transfer coefficient, $\mathrm{W} / \mathrm{m}^{2} \mathrm{~K}$

$\dot{V} \quad$ water volumetric flow rate, $\mathrm{m}^{3} / \mathrm{s}$

$x \quad$ vapor quality

$z \quad$ correction factor

$\alpha \quad$ heat transfer coefficient, $\mathrm{W} / \mathrm{m}^{2} \mathrm{~K}$

$\lambda$ thermal conductivity, $\mathrm{W} / \mathrm{m} \mathrm{K}$

$\mu \quad$ dynamic viscosity, $\mathrm{Pa} \mathrm{s}$

$\rho$ density, $\mathrm{kg} / \mathrm{m}^{3}$

\section{Subscripts}

cond condensation side

cv convective 
in inlet

$G \quad$ vapor phase (fraction)

$\mathrm{Ku} \quad$ Kutatelatze correlation

$L \quad$ liquid phase (fraction)

La Labuntsov correlation

LO liquid phase only

LW laminar-wavy

$\mathrm{Nu}$ Nusselt correlation

out outlet

sat saturation

water water side

WT wavy-turbulent

100 hot water

200 cold water

300 process fluid

\section{REFERENCES}

[1] Rohsenow, W. M., Condensation: Part 1, in Handbook of Heat Transfer Fundamentals, 2d ed., McGraw-Hill, New York, 1985.

[2] Cavallini, A., Longo, G. A., and Rosetto, L., Condensation Heat Transfer and Pressure Drop of Refrigerants in Tubes of Finned Tube Heat Exchangers, in Recent Development in Finned Tube Heat Exchangers: Theoretical and Practical Aspects, DTI Energy Technology, Denmark, 1993.

[3] Boyko, L., and Kruzhilin, G., Heat Transfer and Hydraulic Resistance During Condensation of Steam in an Horizontal Tube and in a Bundle of Tubes, Int. J. Heat Mass Transfer, vol. 10, pp. 361-373, 1967.

[4] Shah, M. M., A General Correlation for Heat Transfer During Film Condensation in Pipes, Int. J. Heat Mass Transfer, vol. 22, pp. 547-556, 1979.

[5] Tovazhnyanski, L. L., and Kapustenko, P. A., Intensification of Heat and Mass Transfer in Channels of Plate Condensers, Chem. Eng. Commun., vol. 31, pp. 351-366, 1984.

[6] Thonon, B., Vidil, R., and Marvillet, C., Recent Research and Developments in Plate Heat Exchangers, J. Enhanced Heat Transfer, vol. 2, no. 1-2, pp. 149-155, 1999.

[7] Di-an, L., and Yongren, L., Steam Condensation in a Vertical Corrugated Duct, Proc. 1988 Natl. Heat Transfer Conf., HTD-Vol 96, vol. 2, pp. 389-393, 1988.

[8] Wang, Z.-Z., and Zhao, Z.-N., Analysis of Performance of Steam Condensation Heat Transfer and Pressure Drop in Plate Condensers, Heat Transfer Eng., vol. 14, no. 4, pp. 32-41, 1993.

[9] Wang, L., Christensen, R., and Sunden, B., Analysis of Steam Condensation Heat Transfer in Plate Heat Exchangers, in G. P. Celata, P. Di Marco, and R. K. Shah (Ed.), Two-Phase Flow Modelling and Experimentation, pp. 375-380, Edizioni ETS, Pisa, Italy, 1999.

[10] Wang, L., Christensen, R., and Sunden, B., Calculation Procedure for Steam Condensation in Plate Heat Exchangers, in Compact Heat Exchangers and Enhancement Technology for the Process Industries, pp. 479-484, Begell House, New York, 1999.

[11] Palm, B., and Thonon, B., Thermal and Hydraulic Performances of Compact Heat Exchangers for Refrigeration
Systems, in Compact Heat Exchangers and Enhancement Technology for the Process Industry, ed. R. K. Shah, pp. 455462, Begell House, New York, 1999.

[12] Panchal, C. B., and Rabas, T. J., Thermal Performance of Advanced Heat Exchanger for Ammonia Refrigeration Systems, Heat Transfer Eng., vol. 14, no. 4, pp. 42-57, 1993.

[13] Kumar, H., The Design of Plate Heat Exchangers for Refrigerants, Proc. Inst. Refrig., 1991-92.5-1, 1992.

[14] Navarro, J. M., and Bailly, A., Compact Brazed Plate Heat Exchangers, in Heat Exchanger Technology: Recent Developments, ed. C. Marvillet, pp. 276-283, Elsevier, Paris, France, 1994.

[15] Chopard, F., Marvillet, C., and Pantaloni, J., Assessment of Heat Transfer Performance of Rectangular Channel Geometries: Implication on Refrigerant Evaporator and Condenser Design, Proc. First European Conf. on Thermal Sciences, IChemE, no. 129, vol. 1, 1992.

[16] Arman, B., and Rabas, T., Condensation Analysis for Plate and Frame Heat Exchangers, HTD-Vol 314, Natl. Heat Transfer Conf., vol. 12, pp. 97-104, ASME, New York, 1995.

[17] Yan, Y.-Y., Liao, H.-S., and Lin, T.-F., Condensation Heat Transfer and Pressure Drop of Refrigerant R-134a in a Plate Heat Exchanger, Int. J. Heat Mass Transfer, vol. 42, pp. 9931006, 1998.

[18] Srinavasan, V., and Shah, R. K., Condensation in Compact Heat Exchangers, J. Enhanced Heat Transfer, vol. 34, pp. 237-256, 1997.

[19] Silver, L., Gas Cooling with Aqueous Condensation, Trans. Inst. Chem. Eng., vol. 25, pp. 30-42, 1947.

[20] Bell, K. J., and Ghaly, M. A., An Approximate Generalized Design Method for Multicomponent/Partial Condensation, AICHE., Symp. Ser., vol. 39, no. 131, pp. 72-79, 1972. 